\title{
A guide to interpretation of neuroimmunological biomarkers in the combined antiretroviral therapy-era of HIV central nervous system disease
}

This article was published in the following Dove Press journal:

Neurobehavioral HIV Medicine

23 August 2010

Number of times this article has been viewed

\author{
Katrina A Morris \\ Nicholas WS Davies \\ Bruce J Brew \\ Department of Neurology, \\ St.Vincent's Hospital, Sydney, \\ Australia and St.Vincent's Centre \\ for Applied Medical Research, Sydney, \\ New South Wales, Australia
}

\begin{abstract}
Biomarkers have emerging roles in diagnosis, prognostication, and treatment monitoring in patients with human immunodeficiency virus-related central nervous system disease. Currently, it is unlikely that a single biomarker will be able to fulfill these roles; rather a combination is more likely. In this review, we use a pathogenetic framework to discuss biomarkers derived from both the blood and cerebrospinal fluid. Emphasis is given to those biomarkers that have a more solid evidence base and those that are easily measurable.
\end{abstract}

Keywords: CSF, biomarker, HAND, HIV, CART

\section{Introduction}

The management of human immunodeficiency virus (HIV)-related central nervous system (CNS) disease requires biomarkers to assist diagnosis, prognostication, and assessment of response to treatment. Currently, no single biomarker alone fulfils any one or more of these roles with appropriate sensitivity or specificity. Combinations of markers may be useful in caring for patients with HIV, ${ }^{1}$ but much work remains to validate these biomarkers with their clinical correlates. ${ }^{2}$ The translation of this work into day-to-day patient care is an ongoing endeavor. A particular challenge is to develop biomarkers that can be used in resource-poor settings, where the majority of disease burden lies. This review aims to outline biomarkers associated with HIV-related CNS disease framing discussion in the context of current understanding of these conditions' neuroimmunological and virological pathogeneses. The clinical phenotype of HIVassociated neurocognitive disorders (HAND) may be changing in treated patients as they age with different risk factors emerging. That acknowledged, this review focuses on the more well-established aspects of HAND.

The biomarkers reviewed are limited to those measured ex vivo in bodily fluids; discussion of in vivo determined imaging-based biomarkers is beyond the scope of this article.

\section{Definitions and background}

\section{HIV-related central nervous system disease}

It was realized early in the HIV/AIDS epidemic that the nervous system is peculiarly sensitive to the effects of the virus. However, the majority of published work describing HIV-related neurological disease describes individuals infected with HIV type-1, clade B. Although this viral clade accounts for the majority of HIV cases in resource-rich countries, different HIV-1 clades are prevalent in other parts of the world and in West Africa, HIV type-2 is commonly found. 
HIV can cause CNS dysfunction at the time of acute seroconversion and thereafter, in untreated patients, with increasing frequency mirroring the severity of immunological decline. In the CNS, HIV has a predilection for the deep white matter, basal ganglia, and possibly spinal cord. The neurotropism of the virus results in the end-stage clinical syndromes of dementia and vacuolar myelopathy, respectively. However, it is recognized that a spectrum of neurocognitive syndromes exist of which HIV dementia is the most severe. Abnormalities less severe than dementia are defined either as asymptomatic neurocognitive impairment or mild neurocognitive disorder. With HIV dementia, these syndromes have recently been recategorized under the umbrella term HAND. ${ }^{3}$

The advent of combined antiretroviral therapy (CART) has profoundly affected the incidence and severity of HAND; its impact is pertinent to the study of biomarkers. Prior to CART, the principle diagnostic aim was to distinguish between potentially treatable CNS diseases caused by opportunistic infection from that resulting directly from the virus. Often conditions overlapped resulting in "layering" of pathologies. ${ }^{4}$ Since CART it is apparent that although HAND incidence has fallen prevalence has increased, there are fewer new cases of HIV dementia. ${ }^{5}$ These epidemiological changes are due to increased longevity of individuals who pre-CART were cognitively impaired; in addition, new cases of milder HAND are recognized in individuals receiving CART who appear to have adequate systemic virological control. It is critically important that studies seeking HAND biomarkers distinguish between individuals with static, albeit severe, impairment from those with active and progressing HAND. Furthermore, since CART, confounds to HAND have changed. In resource-rich countries, the increasing longevity of the HIV-infected cohort has resulted in the increased prominence of factors including hepatitis $\mathrm{C}$ coinfection, aging, and the adverse side effects of CART, such as metabolic derangements. ${ }^{6-8}$ In addition, it is increasingly recognized that CART regimens containing drugs that achieve therapeutic levels in cerebrospinal fluid (CSF) are associated with better cognitive outcomes. ${ }^{9}$ Not all CART regimens have equivalent CNS penetration. This may explain some of the variation in the influence of CART on CSF biomarkers and cognitive outcomes.

The pathogenesis of HIV-related CNS disease is incompletely understood. HIV is thought to enter the brain in infected monocytes soon after infection. Pathologically, activated macrophages and astrocytes, sometimes with multinucleated giant cells, are seen in brain parenchyma, which is named as HIV encephalitis (HIVE). Progression of disease is marked by blood-brain barrier breakdown, rarefaction of white matter, astrocyte apoptosis, dendritic simplification, and neuronal loss. Productive infection occurs in perivascular macrophages and microglia, but restricted nonproductive infection can occur in astrocytes ${ }^{10}$ Potent toxic products arise from viral and cellular gene products. These include the viral proteins as well as proinflammatory cytokines.

\section{Biomarkers}

A biomarker is a "characteristic that is objectively measured and evaluated as an indicator of normal biologic processes, pathogenic processes, or pharmacologic responses to a therapeutic intervention". ${ }^{11}$ Biomarkers can be released intermittently or at a constant rate. The latter are "bulk" markers, the value being directly proportional to affected tissue volume or extent of disease process. Repeat measurement of intermittent markers allows calculation of the "area under the curve" that can strengthen associations; the integral providing better correlation with the comparator. ${ }^{12}$ However, frequent sampling of bodily fluids such as CSF is not practical.

In the case of HIV-related CNS disease, biomarkers are required to indicate presymptomatic involvement of the CNS, to monitor disease-activity as well as response to treatment, and to assist prognostication. Biomarkers can be categorized according to basic principles of disease evolution; namely inflammation, destruction, and repair processes. To document clinically appreciable changes consequent of HIV-related brain disease can require prolonged periods of observation. Therefore, a key additional aim is to identify biomarkers that correlate well with long-term outcome that could be used as surrogate end points in clinical trials.

\section{Biomarkers and compartmentalization}

The study of both HIV-related CNS disease and CNS biomarkers requires appreciation of the barriers between the circulation and the CNS, and the CNS and the intrathecal space. For example, in HIV-infected individuals virus may remain active in the CNS when controlled by medication systemically. Although CSF is considered by many to be a "liquid brain biopsy," in reality it is only a surrogate of the intercellular space of brain parenchyma; however, sampling CSF offers a unique and repeatable opportunity to study CNS metabolism and pathology. ${ }^{12}$ Six barriers pertain to the CSF-containing intrathecal space of which the blood-CSF barrier is the most significant. ${ }^{13}$ Passage of a biomarker across the barrier is affected by the degree of disruption to the barrier and can vary according to the nature of the biomarker, depending on its physicochemical properties as well as its biological features. For example, once activated 
T-lymphocytes can cross the blood-brain barrier. Molecules produced within the CNS that are undetectable, or present in very low concentration in blood, can be measured in CSF alone and CNS origin assumed. However, many molecules, such as immunoglobulin $\mathrm{G}(\mathrm{IgG})$, are found in much greater quantities in blood than in CSF despite intrathecal production occurring in disease states. For these molecules calculation of a CSF-blood index, using comparative measurements of a similar sized non-CNS produced molecule, such as albumin, is required to correct for passive transfer across the blood-CSF barrier.

Furthermore, there are anatomical considerations to the distribution of molecules within the intrathecal space: ventricular CSF has lower protein levels than lumbar CSF. Disease processes that have prominent involvement of the meninges typically result in more marked lumbar CSF changes than processes predominantly affecting brain parenchyma alone.

\section{HIV and blood biomarkers}

Biomarkers of systemic infection activity in HIV, used clinically for monitoring the disease in resource-rich settings, are CD4 T-lymphocyte count and viral load (HIV-RNA). Viral subtypes and drug resistance profiles can assist in medication selection and prognostication. Blood while easier to obtain than CSF is dissociated from the CNS; CD4 count and viral load can only be an approximate guide to probability of HIV-related CNS disease. Although systemic suppression of viral replication can be achieved, this does not necessarily imply CART efficacy within the CNS. In the post-CART era, HAND is increasingly identified in patients with high CD4 counts and undetectable blood viral loads. ${ }^{3}$ This reiterates that CNS compartmentalization necessitates the ability to monitor CNS HIV disease separately to biomarkers of systemic viral replication and immune function.

\section{CNS biomarkers}

In this review, individual biomarkers are discussed in accordance to their pathogenic function in HIV-related CNS disease, a format originally used by Brew and Letendre. ${ }^{14}$ It divides discussion into biomarkers associated with effector cells of disease and their products, viral and host toxins, and markers of neuronal cell damage. Markers to exclude alternative diagnoses and confounds are also described. It is important to note that all of these biomarkers are affected by opportunistic infections. Many of the biomarkers discussed have little data in the post-CART era. In this context, it is important to categorize patients as to whether they are stable on CART vs drug naive or failing treatment, when interpreting biomarker results. A summary of the biomarkers discussed and their utility with CART, where known, is presented in Table 1. Confounds are discussed in detail in the body of the text.

\section{Effector cells Lymphocytes CD4 cell count}

CD4 cell count below $200 / \mu \mathrm{L}$ at least in the pre-CART era was a useful indicator for the risk of HAND, especially dementia, paralleling the increased vulnerability to opportunistic infections. ${ }^{15}$ It is likely that the increased risk of HIV dementia with fall in CD4 count resulted from worsening of immune control leading to increased viral escape and replication.

As discussed earlier, in CART-treated patients the pattern of disease has changed. HAND is now described in patients with normal or near normal CD4 counts and undetectable viral load. ${ }^{8}$ There is a growing evidence base that the nadir, rather than current CD4 count is of greater significance in this group. ${ }^{5,16}$

\section{Beta-2-microglobulin ( $\beta 2 \mathrm{M})$}

$\beta 2 \mathrm{M}$ is predominantly a marker of cytotoxic T-lymphocytes in the CNS. It is the invariant light chain of the major histocompatibility class I (MHC-I) molecule. MHC-I is constitutively expressed on all nucleated cells except neurons. It is particularly highly expressed on the surface of lymphocytes. Nonspecifically raised levels of $\beta 2 \mathrm{M}$ have been described in inflammatory and lymphoproliferative conditions. ${ }^{17} \mathrm{CSF}$ $\beta 2 \mathrm{M}$ concentrations correlate with the risk of HAND in patients with advanced HIV. ${ }^{18}$ The generalizability of $\beta 2 \mathrm{M}$ elevation in neurological involvement of HIV-1 Clade C has recently been described. ${ }^{19}$ However, it is usually not useful in CART-treated patients.

\section{Monocytes CDI $4^{+} / \mathrm{CD} 69^{+}$monocytes}

CD $14^{+} / \mathrm{CD} 69^{+}$monocytes particularly the CD14lo/CD69hi subset in peripheral blood appear to be important in HAND pathogenesis, although they may be nonspecifically elevated in a range of infections. ${ }^{20}$ The prognostic significance in an asymptomatic population is unclear although CART reduced this subset in 1 study. ${ }^{21}$ Recently, levels of HIV-DNA within monocytes measured prior to CART have been demonstrated to correlate with baseline cognitive function as well 
Table I Summary of biomarkers and their utility in CART-treated patients

\begin{tabular}{|c|c|c|c|}
\hline Biomarker & Effect of HIV infection & In HANDa & Useful in patient on CART ${ }^{b}$ \\
\hline \multicolumn{4}{|l|}{ Cerebral spinal fluid } \\
\hline$\beta 2$ microglobulin & Increased & Increased & May indicate treatment failure if high \\
\hline Soluble CDI4s & Increased & Increased & Yes \\
\hline Neopterin & Increased & Increased & May indicate treatment failure if there is further elevation \\
\hline Quinolinic acid & Increased & Increased & If remains elevated \\
\hline s100 & Increased & Increased & Yes \\
\hline Interleukins & Increased & IL-I, IL-6, ILIO & Unknown \\
\hline TNF superfamily proteins & Increased & Increased & Yes \\
\hline Interferons & Increased & Increased & May indicate treatment failure if high \\
\hline $\begin{array}{l}\text { Monocyte chemoattractant } \\
\text { protein-I (MCP-I)/CCL2 }\end{array}$ & Increased & Increased & Yes and may indicate treatment failure if high \\
\hline Fractalkine & May be increased & Increased & Unknown \\
\hline TGF $\beta^{c}$ & Variable & Variable & Unknown \\
\hline $\mathrm{uPAR}^{\mathrm{d}}$ & Increased & Increased & May indicate treatment failure if high \\
\hline HIV RNA & May be increased & Variable & Yes \\
\hline Arachidonic acid metabolites & Increased & Increased & Unknown \\
\hline Nitric oxide & Increased & Variable & Yes \\
\hline Platelet activating factor & May be increased & Increased & No \\
\hline Neurofilament light chain & & Increased & May indicate treatment failure if high \\
\hline Amyloid $\beta 1-42$ & & Decreased & Yes \\
\hline Tau & & Increased & Unknown \\
\hline Sphyngolipids & & Increased & Unknown \\
\hline Protein & Increased & Inconsistent & Unknown \\
\hline ICAM- $\left.\right|^{\mathrm{e}}$ & & Increased & Unknown \\
\hline $\mathrm{MMP}^{\mathrm{f}}$ & & Increased & Unknown \\
\hline \multicolumn{4}{|l|}{ Blood } \\
\hline CD4 count & Important especially if $<200$ & Low count increases risk & Nadir value seems more useful \\
\hline $\mathrm{CDI} 4^{+} / \mathrm{CD} 69^{+}$monocytes & Increased & Increased & Maybe \\
\hline HIV DNA & Increased & Increased & Yes \\
\hline VEGF $^{g}$ & Increased & Increased & Yes \\
\hline
\end{tabular}

Abbreviation: TNF, tumor necrosis factor.

${ }^{a} \mathrm{HIV}$-associated neurocognitive disorder; ${ }^{\mathrm{C} C o m b i n e d ~ a n t i r e t r o v i r a l ~ t h e r a p y ; ~}{ }^{\mathrm{C} T r a n s f o r m i n g}$ growth factor $\beta$; d Urokinase plasminogen activator receptor; Intercellular adhesion molecule; 'Matrix metalloproteinases; ${ }^{\mathrm{V}}$ ascular endothelial growth factor.

as that measured after 48 weeks of antiretroviral therapy. ${ }^{22}$ Furthermore, monocyte HIV-DNA load of $3.5 \log _{10}$ or more predicted all cases of HIV dementia. However, these findings await validation in larger, non-Thai, cohorts.

\section{Soluble CDI4s (sCDI4)}

CD14 exists in both soluble and membrane forms, predominantly on human monocytes. ${ }^{23}$ It is a coreceptor for lipopolysaccharide and modulates the cell's response to infection. It is released by stimulated monocytes in vitro. Elevations in serum concentration have been associated with disease progression in patients with HIV. ${ }^{24,25}$ Ryan et al ${ }^{26}$ described higher plasma concentrations in cognitively impaired patients on CART compared with cognitively unimpaired patients. In distinction to other markers of macrophage activation in the CNS, sCD14 may derive primarily from trafficking monocytes and perivascular macrophages, rather than from native microglia. ${ }^{27}$ Thus, sCD14 levels may indicate differences between individuals of CNS infiltration by immune cells.
If levels of sCD 14 correlate with those of $\mathrm{CD} 14^{+} / \mathrm{CD} 69^{+}$cells, they may prove easier for monitoring as SCD14 can be tested using a simple enzyme-linked immunosorbent assay. Soluble CD14 levels can decrease with CART but, whereas raised levels are nonspecific, such elevated levels may identify patients at risk of subsequent neurological injury. ${ }^{21,28}$

\section{Neopterin}

Neopterin serves as a marker for monocytes, macrophages, microglia, and to a lesser extent, astrocytes. It is a product of guanosine triphosphate metabolism that is produced mainly by monocytes, macrophages, microglia, and astrocytes. ${ }^{29,30}$ High concentrations have been found in the CSF of patients with both opportunistic CNS infections and HIV dementia. In addition, levels decrease with antiretroviral treatment. ${ }^{29}$ This finding has been replicated in HIV-1 clade C. ${ }^{19}$ Elevated CSF neopterin correlates with HIV dementia severity. ${ }^{29}$ In patients with advanced HIV disease, elevated levels are associated with increased risk of dementia. ${ }^{31}$ Furthermore, in 1 study 
after 2 years of viral suppression only $55 \%$ of patients had normal CSF neopterin. ${ }^{32}$ The implications of this finding to the risk of later development of HAND are not known.

\section{Quinolinic acid (QUIN)}

QUIN is a product of the kynurenine pathway for tryptophan metabolism. ${ }^{33}$ It is produced by monocytes in response to interferons, especially interferon $\gamma$ and HIV proteins among other agents. Notably, QUIN is not only a marker of monocyte activation but also a toxin being an excitotoxic agonist at $N$-methyl D-aspartate (NMDA) receptors. It can also cause cell death through lipid peroxidation and the generation of free radicals. ${ }^{34}$ QUIN is at present only measurable using gas chromatography/mass spectroscopy, which severely limits its clinical utility.

Increased CSF QUIN may be seen in opportunistic infections and HIV dementia; in the latter concentrations correlate with dementia severity. ${ }^{33}$ One small study showed that elevated CSF concentrations increased the risk of dementia. ${ }^{35}$ QUIN cannot cross an intact blood-brain barrier making CSF levels a more specific marker of disease activity within the brain. Thus, raised CSF levels usually indicate an intrathecal process and have been shown to respond rapidly to antiretroviral treatment. ${ }^{33,36}$

\section{Microglia}

CSF markers for microglia are currently inferred from those previously discussed with respect to monocytes. There are no specific markers for microglia at present. In pathological studies, the degree of microglial activation is the best correlate for the presence and severity of HAND ${ }^{37}$ Early neuropathological studies used ferritin as a marker for activated microglia but CD68 is now more usually used as a marker. ${ }^{38}$ Ferritin is readily measurable in CSF and it is used clinically as a biochemical marker of recent subarachnoid hemorrhage. CSF ferritin levels have been studied in HIV neurological disease but where elevated levels were found these did not show specificity to HIV-mediated CNS disease, as opposed to opportunistic infections. ${ }^{39}$ Development of a specific CSF marker of microglial activation would be of significant clinical benefit.

\section{Astrocytes}

\section{S- 100}

$\mathrm{S}-100$ is an acidic calcium binding protein, which exists in dimers containing $\alpha$ and/or $\beta$ subunits. S100 $\beta$, which contains two $\beta$ subunits, is found almost exclusively in astrocytes and elevation in levels are associated with astrocytosis. ${ }^{40}$
CSF S100 $\beta$ levels are elevated in many inflammatory, degenerative, and traumatic CNS conditions. Raised S100 $\beta$ is associated with increased severity of HAND and more rapid progression to dementia. ${ }^{40}$ Pathogenically, high levels may lead to neuronal apoptosis..$^{41}$ Recently, Woods et al ${ }^{42}$ associated elevations in CSF S100 $\beta$ with decreased verb word generation counts and executive functioning independently of current CD4 count, HIV dementia score and CART use. CSF S100 $\beta$ did not correlate with deficits of psychomotor speed or semantic memory.

\section{Glial fibrillary acid protein}

Glial fibrillary acid protein is an astrocyte structural protein, the exact function of which is unclear. Although levels have been described to change in neurodegeneration, it does not appear to correlate with HIV-associated CNS disease.

\section{Modulators}

Immune cells are the primary targets of HIV. Thus biomarkers concerned with the activation or suppression of the immune system are a rational focus of research. Many immune functions and cellular interactions of the immune system are modulated by cytokines. This diverse group of signaling peptides and glycoproteins is produced by and acts on specific cells, eliciting characteristic effects on growth, mobility, differentiation and function of target cells. These in turn regulate immune and inflammatory responses as well as hematopoiesis, angiogenesis, and healing. ${ }^{43}$

\section{Interleukins}

The most studied interleukins are concerned with regulation of inflammation and activation of the immune response and are produced by cells important to the neuropathogenesis of HIV. There are 2 types of helper T-lymphocytes and each type produces a particular group of interleukins with distinct targets. Those produced by T helper 1 (Th1) cells (eg, interleukin-2 [IL-2]) generally activate macrophages, whereas Th2 cell derived (eg, IL-6 and IL-10) factors generally activate B-lymphocytes. Others, such as IL-1, are produced by macrophages as well as other antigen presenting cells and promote inflammation and lymphocyte homing.

There is an ever-increasing number of interleukins but most studies in HAND (the majority predating CART) have focused on 3 interleukins: IL-1, IL-2, and IL-6. Among 6 studies that measured IL-1 in CSF, 4 identified a relationship with HAND, either in adults ${ }^{44,45}$ or in children. ${ }^{46,47}$ Most of the 9 studies that measured IL-6 in CSF, also identified associations with brain injury, in either adults ${ }^{44,48-50}$ or children. ${ }^{46,47}$ 
In contrast, none of the studies of IL-2 identified associations with neurological disease. In fact, only 3 studies even compared levels of IL-2 or its soluble receptor in paired CSF and blood samples, to a measure of brain injury. ${ }^{44,51,52}$ Of the interleukins measured in other CSF studies, ${ }^{53-55}$ only IL-10 elevation in CSF in comparison to paired serum samples was associated with HAND by 1 of the 2 largest studies in this series. ${ }^{56}$

IL-1, IL-6, and IL-10 are mainly produced by antigen presenting cells such as macrophages in contrast to IL-2 produced by Th1 cells. This is consistent with the importance of macrophages but not Th1 cells in the neuropathogenesis of HIV. Th2 lymphocytes do produce IL-6 and IL-10 and so may also be involved in neuropathogenesis.

\section{Tumor necrosis factor (TNF) superfamily proteins}

The TNF family of molecules is involved in immune regulation and inflammation. ${ }^{57,58}$ Receptors for TNF and soluble molecules such as Fas and CD30 are considered closely related proteins. ${ }^{59-62}$ The prototype of this group is TNF- $\alpha$ which is produced by macrophages and microglia and is central to several pathogenic processes. ${ }^{63}$ In HIV disease, it can upregulate HIV replication and TNF- $\alpha$ mRNA levels are elevated in the brain tissue of HAND patients. ${ }^{64-66}$

Most studies that have identified TNF- $\alpha$ in CSF have also identified markers of brain tissue injury, HIV-RNA in CSF, and focal CNS damage. ${ }^{45,49,64,67-72}$ Positive studies that have reported on TNF superfamily proteins in CSF to date have identified links with HAND. The endogenous regulation of TNF- $\alpha$ makes it difficult to measure in body fluids. Strong evidence exists that TNF- $\alpha,{ }^{69}$ sTNFRs, $^{73}$ and $\mathrm{sFas}^{74}$ can be detected in body fluids despite antiretroviral therapy, supporting that these proteins might be useful biomarkers of ongoing neuroinflammation in treated individuals.

\section{Interferons and the molecules they induce}

Interferons are cytokines and are grouped by their immunomodulation functions and target receptors. They are classified into type-1 (IFN $\alpha, \beta, \omega$, and $\kappa$ ) and type-2 (IFN $\gamma$ ). In the brain, astrocytes and microglia produce mainly IFN $\alpha$. Endogenous IFN $\alpha$ may help protect the brain from viral infections but exposure to high concentrations or for prolonged periods may damage the brain. Transgenic mice that overproduce IFN $\alpha$ in astrocytes have a high incidence of severe neuropathology, with intractable seizures and early death. ${ }^{75}$ The expression of IFN $\alpha$ is elevated in HIVE and correlates with the severity of ante mortem cognitive impairment. Recently, in a mouse model of HIVE, the use of IFN $\alpha$ neutralizing antibodies led to a decrease in cognitive deficits but its potential role in humans remains to be investigated. ${ }^{76}$

All 3 studies of IFN $\alpha$ in CSF have shown an association between higher levels and increased risk of HAND. ${ }^{48,77,78}$ Two of these also linked elevated IFN $\alpha$ and higher HIVRNA levels in $\mathrm{CSF}^{48,77}$ consistent with ineffective antiviral activity. Three of 4 studies of CSF IFN $\gamma$ demonstrated higher levels in HIV infection independent of cognition, ${ }^{51,67,79}$ the fourth was not able to identify IFN $\gamma$ in $\mathrm{CSF}^{44}$ Only Nolting et $\mathrm{al}^{67}$ demonstrated increased IFN $\gamma$ (with IL-1 $\alpha$, IL-15, and TNF- $\alpha$ ) in HAND patients compared with HIV-infected nondemented controls; although notably all the other studies were published prior to the advent of CART.

IP-10, an interferon-inducible protein has been reported in 5 CSF studies. Three have compared IP-10 levels with HIV-RNA levels in CSF and found statistically significant correlations. ${ }^{73,80,81}$ Gisolf et $\mathrm{al}^{73}$ identified that IP-10 was elevated in some patients in spite of apparent HIV-RNA control, similar to their findings with sTNFR-II, whereas Probasco et $\mathrm{al}^{81}$ have found IP-10 is not significantly elevated in HIV controllers or those with suppressed viral load on treatment. Two studies compared IP-10 and brain injury, identifying both links between higher levels and adverse neurological outcomes. ${ }^{53,82}$

\section{Chemokines}

Monocyte chemoattractant protein-I (MCP-I)

MCP-1, which is also known as CCL2, is a chemokine associated with chemotaxis of monocytes across the bloodbrain barrier; ${ }^{83} \mathrm{HIV}$ and QUIN induce its expression by astrocytes. ${ }^{84,85}$ Given the critical role that monocytes are thought to play in HAND pathogenesis, factors promoting monocyte CNS ingress are potentially useful biomarkers. Human studies have shown upregulated MCP-1 expression on macrophages in patients dying with HIVE. ${ }^{86}$ Eight of 9 studies have shown a link between higher MCP-1 levels in CSF and worse outcomes. ${ }^{55,69,84,87-91}$ Importantly, it has been particularly studied in the post-CART era. A recent study has demonstrated that "elite controllers," who are HIV-infected individuals who have viral loads $<50$ copies/mL without CART, have CSF MCP-1 levels similar to CART-treated and noninfected individuals. ${ }^{81}$

\section{Other CC chemokines}

A smaller number of studies have compared neurological outcomes and levels of other CC chemokines: MIP-1 $\alpha$, 
MIP-1 $\beta$, and RANTES. These chemokines bind to CCR5, the receptor commonly used for HIV entry into microglia and lymphocytes. ${ }^{92}$ They are implicated in HIV neuropathogenesis through their identification in HIVE brain tissue and tissue from a simian HAND model. ${ }^{93-96}$ Their elevation has not been consistently demonstrated in published CSF studies ${ }^{55,97}$ and particularly in treated individuals it has been difficult to detect these chemokines. ${ }^{53}$

\section{Fractalkine}

Fractalkine is a chemokine that binds to CX3CR1 appears important in reducing neurotoxicity associated with activated microglia. ${ }^{98}$ Two studies have demonstrated nonspecific elevations in CSF fractalkine in HIV-positive patients with neurological sequelae including dementia. ${ }^{99,100}$ This is not immediately reconciled with in vitro data suggesting fractalkine is neuroprotective. Elevated levels may suggest a host attempt at neuroprotection. The Magnetic Resonance Spectroscopy consortium group demonstrated that lower CSF fractalkine levels were associated with lower neuronal pattern scores on proton magnetic resonance spectroscopy. ${ }^{101}$

\section{Transforming growth factor beta (TGF $\beta$ )}

TGF $\beta$ contributes to down regulation of T-lymphocyte and macrophage activation, modulation of proinflammatory cytokines, and protection against neuronal excitotoxicity secondary to HIV infection. ${ }^{102}$ In HIV CNS disease, TGF $\beta$ is produced by CD8 lymphocytes, astrocytes, and microglia. CSF TGF $\beta$ concentrations are elevated in mild HAND but undetectable in more severe disease. ${ }^{48,103}$ The influence of CART and the prognostic significance of TGF $\beta$ are not known.

\section{Urokinase plasminogen activator receptor (UPAR)}

Urokinase plasminogen activator receptor (UPAR) and its ligand uPA have an important role in cell migration and extracellular proteolysis. It is elevated in brain tissue in all opportunistic infections in HIV-positive patients, except cryptococcosis, and it is also elevated in HAND. ${ }^{104}$ Raised CSF soluble UPAR levels are seen in HAND and decline significantly with CART. ${ }^{105}$

\section{Toxins \\ Viral}

\section{HIV-RNA viral load}

HIV-RNA viral load is a marker of active viral replication; however, plasma HIV-RNA levels have limited utility as a biomarker for HAND. CSF HIV-RNA is also nonspecific with levels raised in asymptomatic patients as well as those with opportunistic infections and HAND. ${ }^{106-108}$ In CART-naive patients with HAND, the severity of disease is correlated with CSF HIV-RNA levels ${ }^{106,109}$ and falls with antiretroviral treatment. ${ }^{110}$ In those with HAND receiving CART, CSF viral load does not predict progression. ${ }^{69}$ Whereas, in cognitively asymptomatic subjects on CART, an elevated CSF viral load (>200 copies $/ \mathrm{mL}$ ) is reported to predict progression of cognitive impairment at a median of 1 year. ${ }^{111}$ The risk of HAND in "elite" viral controllers is not known although in a recent study of such patients no evidence of intrathecal inflammation was found on CSF examination. ${ }^{81}$

Although uncommon, in CART-treated patients HAND can still develop despite an undetectable HIV-RNA level in the CSF. ${ }^{69,112,113}$ There are many proposed mechanisms for this. First, that this indicates HAND that has not fully responded to CART with residual permanently damaged brain tissue, so-called inactive HAND. ${ }^{112}$ Second, that clinically apparent neurological deficit is driven by a coexistent illness, such as Hepatitis C, rather than HIV. ${ }^{114,115}$ Third, that HIV initiates the process, which then becomes autonomous of the virus. ${ }^{69}$ Finally, some individuals develop an immune reconstitution disorder after initiation of CART, leading to clinical decline in neurological function, as a consequence of increased CNS immune activation. ${ }^{116}$

\section{HIV-DNA}

HIV-DNA results from reverse transcription of viral RNA and can be integrated into chromosomal DNA. Plasma levels reflect latent infection and appear to correlate with HAND, being elevated in CART-treated and untreated patients with clinical HAND. ${ }^{117,118}$ Data regarding CSF HIV-DNA have not been reported. This may be due to technical difficulties in measurement due to low cell counts in CSF. However, as discussed earlier, HIV-DNA measured in peripheral monocytes appears more strongly associated with HAND and might be a useful biomarker.

\section{HIV proteins}

HIV proteins that are encoded on the virus's genome include gp120, Nef, Tat, gp41, and VPR. In vitro toxicity to neural cells has been demonstrated; often through the proteins' actions on cell signaling pathways, or through generation of other toxic factors. ${ }^{119} \mathrm{HIV}$ proteins have proved difficult to measure in CSF, consequently limiting their use as biomarkers.

\section{Host toxins}

Host toxins include arachidonic acid metabolites, nitric oxide, and platelet activating factor (PAF) as well as 
previously discussed neurotoxins: QUIN, S100 $\beta$, interferons, interleukins, and TNF- $\alpha$.

\section{Arachidonic acid metabolites}

Arachidonic acid metabolites, which include prostaglandins, are the product of cyclooxygenase metabolism of lipids rich in arachidonic acid. Levels were significantly correlated with the presence and severity of HAND, as well as with $\beta 2 \mathrm{M}$ and neopterin, in studies before the introduction of CART. The effect of antiretroviral drugs and the significance of elevated concentrations with regards to direct disease causation is not known. ${ }^{120}$

\section{Nitric oxide}

Nitric oxide is considered to be an important neurotoxin in HAND, where it is predominantly produced by macrophages and microglia. CSF concentrations of nitric oxide metabolites are raised in opportunistic CNS infections associated with HIV, ${ }^{121}$ which may result from damage to the blood-brain barrier. ${ }^{122}$ Pre-CART, no increase in CSF levels of nitric oxide and its metabolites were noted in HAND. ${ }^{123}$ However, a more contemporary study has demonstrated increased CSF nitric oxide and 3-nitrotyrosine modified proteins among those who subsequently develop cognitive decline or have used intravenous illicit drugs. ${ }^{124}$ In HAND brain tissue, there is evidence of increased activity of nitric oxide's associated enzyme. The discrepancy between these 2 studies could be due to differences between the cohorts in proportion of active neurodegeneration cases or frequency of intravenous drug use.

\section{Platelet activating factor}

PAF is produced by infected or activated monocytes. Although it has many actions in HIV-associated diseases there is convincing evidence that its neurotoxicity is at least in part mediated by NMDA receptor activation. ${ }^{125-128}$ PAF levels are nonspecifically elevated in HAND. In vitro tests suggest that CART regimens may have anti-PAF effects ${ }^{129}$ and a PAF antagonist has shown promising results in a mouse model of HIVE. ${ }^{130}$ However, a case-controlled study of HIV-positive patients starting CART showed no significant change in CSF PAF levels over 4 months of treatment. ${ }^{131}$

\section{Target cell}

\section{Neuron}

\section{Neurofilament light chain (NFL)}

NFL is an essential part of the core of the triplet protein neurofilament. Neurofilament is a major structural protein of neurons and is found mostly in large myelinated neurons. ${ }^{132}$ Its main function is to maintain axonal caliber. NFL is significantly raised in HAND and levels rise with CART interruption. ${ }^{133,134}$ In a longitudinal study, a group of patients who subsequently developed HAND had raised NFL levels on CSF taken up 2 years prior in comparison to CD4-matched controls. ${ }^{135}$ This suggests elevated NFL may be a preclinical indicator of risk of HAND in the next 2 years. NFL levels decrease in the majority of patients treated with CART and this is paralleled by a clinical improvement in severe HAND. ${ }^{136}$ Neurofilament heavy chain, which in vitro is more stable than NFL, is elevated in a variety of peripheral and CNS pathologies characterized by neuronal injury including multiple sclerosis and the Guillain-Barré syndrome. ${ }^{137-139}$ Thus far measurement of CSF neurofilament heavy chain as a biomarker for HAND has not been reported.

\section{Amyloid and Tau amyloid precursor proteins}

Amyloid precursor protein are ubiquitously expressed transmembrane proteins with pathogenic significance. When cleaved by $\alpha$-secretase a soluble form sAPP $\alpha$ is made. Soluble APP $\alpha$ does not form part of the amyloid generation pathway. By contrast if cleaved by $\beta$-secretase the soluble form sAPP $\beta$ is made which can be further metabolized to $A \beta$ peptides including $A \beta_{1-42}$ which are the major constituents of amyloid plaques. ${ }^{140} \mathrm{Tau}$ is a structural neuronal protein. There are 2 dominant forms that can be measured: total tau (t-tau) and phosphorylated tau (p-tau). Both nonspecifically represent neuronal damage, though $\mathrm{p}$-tau is more often elevated in patients with Alzheimer disease (AD). ${ }^{141}$

Aging populations are associated with an increased incidence of dementia. Thus as the HIV-infected cohort ages, it is increasingly important to distinguish between HAND and AD. A 442 is lower in HAND patients in comparison to both HIV-positive nondementia patients and HIV-negative patients with dementia. ${ }^{142,143}$ In the Brew et al ${ }^{142}$ cohort, not on CART, p-tau was increased in HIV dementia in comparison to both $\mathrm{AD}$ patients and normal controls. By contrast, in the Clifford et $\mathrm{al}^{143}$ cohort, on CART, t-tau and p-tau were increased in the AD patients but were decreased in the HIV positive whether with normal or impaired cognition. ${ }^{143}$ The reason for the differences between the 2 studies p-tau levels is unclear although it may suggest that treatment with CART decreases $\mathrm{t}$-tau and p-tau, and this is perhaps an indicator of the role of CART with respect to HAND prevention. A recent retrospective study showed decreased sAPP $\alpha$ and $\beta$ in patients with both HAND and opportunistic CNS infection distinguishing them from HIV-positive asymptomatic controls and $\mathrm{AD}$ 
patients. ${ }^{140}$ The relationship between NFL and tau elevation is not clear although they are both markers of damage to neurons with NFL predominantly indicating damage to large myelinated axons.

\section{Sphingomyelin and ceramide}

Sphingomyelin and ceramide are intracellular membrane sphingolipids that are particularly high in concentration in myelin. However, sphingolipids originating from peripheral myelinated axons in nerve roots released into CSF can confound assessment of CNS myelin release. Their presence in the CSF is evidence of cell destruction. In a study of 48 patients, elevated levels were found to correlate with cognitive decline and clinically stable dementia. ${ }^{144}$ The same group found increased levels of vitamin $\mathrm{E}$ and triglyceride C52 in HAND patients with active cognitive decline. These antioxidants are lowered in AD and aging and are thought to be neuroprotective. This may suggest an attempt by the host to oppose the neurodegeneration of HAND. Elevated sphingolipid was associated with inactive HIV dementia, whereas elevated ceramide with active disease.

\section{Endothelial cells/blood-brain barrier CSF proteins and their indices}

Albumin and IgG are large proteins found in low concentration in the CSF of healthy individuals with an intact blood-CSF barrier. Elevated levels of CSF albumin, and to a lesser extent CSF protein, indicate impairment of the blood-CSF barrier. IgG can be elevated in CSF because of blood-CSF barrier impairment or secondary to intrathecal synthesis. Intrathecal synthesis of IgG is a common finding in HIV patients with or without neurological disease or opportunistic infections. ${ }^{145}$ The albumin ratio, a quantitative measure of blood-CSF barrier impairment, is reported in HIV to be elevated; however, links with HIV neurological disease have been inconsistent. ${ }^{131,146-148}$ Pre-CART studies typically demonstrated an abnormal albumin ratio, which was associated with decline in CD4 count. Abdulle et al ${ }^{145}$ studied the change in albumin ratio and $\operatorname{IgG}$ index in neurologically asymptomatic individuals starting CART (median CD4 count 185 cells $/ \mu \mathrm{L}$ ) finding no significant difference in either parameter after 2 years therapy. In this series, although $56 \%$ had abnormal IgG index prior to CART, only $5 \%$ had an abnormal albumin ratio. Therefore, the lack of significant change in albumin ratio with treatment is more likely a function of earlier initiation of therapy resulting in fewer patients at entry having demonstrable blood-CSF barrier dysfunction than lack of response to therapy. One study found strong associations between CSF total protein levels and cognitive improvements after changes in antiretroviral medications. ${ }^{74}$ However, until there are further corroborating data, CSF total protein cannot be considered a reliable marker of HAND, as HAND may occur seemingly with an intact blood-CSF barrier.

\section{Vascular endothelial growth factor (VEGF)}

VEGF is a potent angiogenic and mitogenic peptide. There is 1 study of serum and CSF VEGF that showed elevations in only serum levels in patients with HAND. Even after viral suppression with CART the VEGF levels, decreased but were increased higher than those seen in patients without HAND. ${ }^{149}$ This may suggest a role as a serial marker to monitor for improvement post-CART introduction.

\section{Intercellular adhesion molecules (IACM)}

HIV gp120 and proinflammatory cytokines can upregulate the expression of adhesion molecules, including ICAM-1 on the luminal surface of brain microvascular endothelial cells. ${ }^{150}$ The soluble form sICAM-1 has been studied in CSF. The levels of HIV-positive subjects is higher than noninfected controls without neuroinflammatory disease ${ }^{151}$ but lower than subjects with other causes of meningeal inflammation. ${ }^{152}$

\section{Matrix metalloproteinases (MMPs)}

MMPs are a family of neutral proteases that are important to normal development and have been implicated in many pathological processes. In the CNS, they can degrade components of the basal lamina leading to blood-brain barrier disruption. ${ }^{153}$ MMP-9 has been shown to be elevated in HIV-positive subjects with neurological deficits or CNS opportunistic infections. ${ }^{154-156}$

\section{Proteomics}

Recent combined mass spectrometry and 2D Western blot analysis of the CSF protein content in patients with and without cognitive impairment has sought to define a "protein fingerprint" of HIV-associated brain disease. ${ }^{157}$ Laspuir ${ }^{158}$ identified several candidate biomarkers that are linked to immune signaling and macrophage function in the CNS in their Puerto Rican cohort of predominantly Hispanic women with HAND. Validation in large cohorts remains essential especially as each study has identified different combinations of proteins, although cystatin appeared in both groups' works. Profiles may differ depending on stage and activity of HAND and duration on CART. 


\section{Biomarkers to exclude other disease}

Several simple blood biomarkers are important in the exclusion of mimics of HAND.

\section{Vitamin BI2, red cell folate, and thyroid function}

Vitamin B12, red cell folate, and thyroid function are commonly assayed in patients with dementia. They are appropriate to check in HAND patients as B12 and folate deficiency can mimic dementia as well as being associated with myelopathy and neuropathy. Hypothyroidism can on occasions resemble HAND, especially with respect to psychomotor slowing.

\section{CSF leucocyte count}

CSF leucocyte count can be useful to indicate causes other than HAND. If the CSF leucocyte count is above 50 cells $/ \mu \mathrm{L}$ HIV alone is unlikely, especially when the CD4 count is below 200 cells $/ \mu \mathrm{L}$ and additional conditions such as cryptococcal meningitis should be considered. The differential can be useful in guiding further investigation. For example, a polymorphonuclear pleocytosis raises the possibility of cytomegalovirus encephalitis.

\section{Conclusion}

As discussed, the number of biomarkers that show promise in indicating aspects of HIV-related neuroinflammation and treatment response is large. However, at present no one marker can be used to predict the presence of HAND or prognosis following treatment. Some markers have greater utility in treatment monitoring, whereas others may assist in prognostication. It has been proposed that a combination of markers be used in ongoing trials. ${ }^{1,2}$ This approach would combine indicators of neuronal damage (eg, NFL), HIV activity (eg, HIV-RNA), and neuroinflammation (eg, MCP-1) to create a combined picture of ongoing CNS activity and disease risk.

What biomarkers can the clinician usefully use at present to guide management? This depends upon whether the patient is receiving CART at the time of assessment. In patients who are CART-naive, CD4 count ( $>200$ cells $/ \mu \mathrm{L}$ ), and undetectable CSF viral load $(<50$ copies $/ \mu \mathrm{L})$ are useful as they would be unusual for HAND. Among CART-treated patients, nadir CD4 count is a more useful biomarker. CSF protein is elevated in HIV dementia, which may aid distinction from other neurodegenerative diseases but does not aid exclusion of opportunistic infections.
As the HIV-positive population ages the distinction between HAND and other dementias will become increasingly important and challenging. The amyloid and tau family of proteins may be particularly useful in this group. Markers of repair and inactive disease are also needed, particularly to aid identification of individuals who might benefit from "neuro-intensification" of their CART regimen.

The ideal sole HAND biomarker to replace the combinatorial approach required at present depending on clinical circumstance, should be sensitive (identifying individuals in an asymptomatic state) but have disease specificity, be a "bulk" marker, be present in significant concentration in blood (or be measurable noninvasively), show a response to treatment, and be easily and cost-effectively measured. The search for such a biomarker continues.

\section{Acknowledgment}

NWSD is grateful to the Eleanor Peel Medical Trust for financial support.

\section{Disclosure}

The authors report no conflicts of interest in this work.

\section{References}

1. Price RW, Epstein LG, Becker JT, et al. Biomarkers of HIV-1 CNS infection and injury. Neurology. 2007;69:1781-1788.

2. Gisslen M, Hagberg L, Rosengren L, et al. Defining and evaluating HIV-related neurodegenerative disease and its treatment targets: a combinatorial approach to use of cerebrospinal fluid molecular biomarkers. J Neuroimmune Pharmacol. 2007;2:112-119.

3. Antinori A, Arendt G, Becker JT, et al. Updated research nosology for HIV-associated neurocognitive disorders. Neurology. 2007;69: 1789-1799.

4. Brew B. Principles of HIV neurology. HIV Neurology. Vol 1. New York: Oxford University Press; 2001:32-35.

5. Robertson KR, Smurzynski M, Parsons TD, et al. The prevalence and incidence of neurocognitive impairment in the HAART era. AIDS. 2007;21:1915-1921.

6. Dore GJ, Correll PK, Li Y, Kaldor JM, Cooper DA, Brew BJ. Changes to AIDS dementia complex in the era of highly active antiretroviral therapy. AIDS. 1999;13:1249-1253.

7. Brew BJ, Dore G. Decreasing incidence of CNS AIDS defining events associated with antiretroviral therapy. Neurology. 2000;55:1424.

8. Dore GJ, McDonald A, Li Y, Kaldor JM, Brew BJ. Marked improvement in survival following AIDS dementia complex in the era of highly active antiretroviral therapy. AIDS. 2003;17:1539-1545.

9. Letendre S, Marquie-Beck J, Capparelli E, et al. Validation of the CNS penetration-effectiveness rank for quantifying antiretroviral penetration into the central nervous system. Arch Neurol. 2008;65:65-70.

10. Budka H. The neuropathology of HIV-associated brain disease. In: Gendelman HE, Grant I, Everall IP, Lipton, SA, Swindells S, editors. The neurology of AIDS. 2nd ed. New York: Oxford University Press; 2005:375-391.

11. Floyd E, McShane TM. Development and use of biomarkers in oncology drug development. Toxicol Pathol. 2004;32(Suppl 1):106-115.

12. Giovannoni G. Multiple sclerosis cerebrospinal fluid biomarkers. Dis Markers. 2006;22:187-196. 
13. Thompson EJ. Cerebrospinal fluid. J Neurol Neurosurg Psychiatry. 1995;59:349-357.

14. Brew BJ, Letendre SL. Biomarkers of HIV related central nervous system disease. Int Rev Psychiatry. 2008;20:73-88.

15. Brew BJ. Markers of AIDS dementia complex: the role of cerebrospinal fluid assays. AIDS. 2001;15:1883-1884.

16. Cysique LA, Maruff P, Brew BJ. Variable benefit in neuropsychological function in HIV-infected HAART-treated patients. Neurology. 2006;66:1447-1450.

17. Brew BJ. Medical management of AIDS patients. Central and peripheral nervous system abnormalities. Med Clin North Am. 1992;76: 63-81.

18. Brew BJ. Human immunodeficiency virus in brain and correlation with dementia. Ann Neurol. 1996;39:828-829.

19. Kamat A, Ravi V, Desai A, Satishchandra P, Satish KS, Kumar M. Estimation of virological and immunological parameters in subjects from South India infected with human immunodeficiency virus type 1 clade $\mathrm{C}$ and correlation of findings with occurrence of neurological disease. J Neurovirol. 2009;15:25-35.

20. Pulliam L, Gascon R, Stubblebine M, McGuire D, McGrath MS Unique monocyte subset in patients with AIDS dementia. Lancet. 1997;349:692-695.

21. Kusdra L, McGuire D, Pulliam L. Changes in monocyte/macrophage neurotoxicity in the era of HAART: implications for HIV-associated dementia. AIDS. 2002;16:31-38.

22. Valcour VG, Shiramizu BT, Sithinamsuwan P, et al. HIV DNA and cognition in a Thai longitudinal HAART initiation cohort: the SEARCH 001 Cohort Study. Neurology. 2009;72:992-998.

23. Landmann R, Muller B, Zimmerli W. CD14, new aspects of ligand and signal diversity. Microbes Infect. 2000;2:295-304.

24. Lien E, Aukrust P, Sundan A, Muller F, Froland SS, Espevik T. Elevated levels of serum-soluble CD14 in human immunodeficiency virus type 1 (HIV-1) infection: correlation to disease progression and clinical events. Blood. 1998;92:2084-2092.

25. Nockher WA, Bergmann L, Scherberich JE. Increased soluble CD14 serum levels and altered CD14 expression of peripheral blood monocytes in HIV-infected patients. Clin Exp Immunol. 1994;98: 369-374.

26. Ryan LA, Zheng J, Brester M, et al. Plasma levels of soluble CD14 and tumor necrosis factor-alpha type II receptor correlate with cognitive dysfunction during human immunodeficiency virus type 1 infection. J Infect Dis. 2001;184:699-706.

27. Cauwels A, Frei K, Sansano S, et al. The origin and function of soluble CD14 in experimental bacterial meningitis. J Immunol. $1999 ; 162: 4762-4772$.

28. Sun B, Abadjian L, Rempel H, Calosing C, Rothlind J, Pulliam L. Peripheral biomarkers do not correlate with cognitive impairment in highly active antiretroviral therapy-treated subjects with human immunodeficiency virus type 1 infection. J Neurovirol. 2010;16:115-124.

29. Brew BJ, Bhalla RB, Paul M, et al. Cerebrospinal fluid neopterin in human immunodeficiency virus type 1 infection. Ann Neurol. 1990;28: 556-560.

30. Hamerlinck FF. Neopterin: a review. Exp Dermatol. 1999;8:167-176.

31. Brew BJ, Dunbar N, Pemberton L, Kaldor J. Predictive markers of AIDS dementia complex: CD4 cell count and cerebrospinal fluid concentrations of beta 2-microglobulin and neopterin. J Infect Dis. 1996;174:294-298.

32. Abdulle S, Hagberg L, Svennerholm B, Fuchs D, Gisslen M. Continuing intrathecal immunoactivation despite two years of effective antiretroviral therapy against HIV-1 infection. AIDS. 2002;16:2145-2149.

33. Heyes MP, Brew BJ, Martin A, et al. Quinolinic acid in cerebrospinal fluid and serum in HIV-1 infection: relationship to clinical and neurological status. Ann Neurol. 1991;29:202-209.

34. Behan WM, McDonald M, Darlington LG, Stone TW. Oxidative stress as a mechanism for quinolinic acid-induced hippocampal damage: protection by melatonin and deprenyl. Br J Pharmacol. 1999;128 1754-1760.
35. Martin A, Heyes MP, Salazar AM, et al. Progressive slowing of reaction time and increasing cerebrospinal fluid concentrations of quinolinic acid in HIV-infected individuals. $J$ Neuropsychiatry Clin Neurosci. 1992;4:270-279.

36. Valle M, Price RW, Nilsson A, Heyes M, Verotta D. CSF quinolinic acid levels are determined by local HIV infection: cross-sectional analysis and modelling of dynamics following antiretroviral therapy. Brain. 2004;127:1047-1060.

37. Glass JD, Fedor H, Wesselingh SL, McArthur JC. Immunocytochemical quantitation of human immunodeficiency virus in the brain: correlations with dementia. Ann Neurol. 1995;38:755-762.

38. Yoshioka M, Shapshak P, Sun NC, et al. Simultaneous detection of ferritin and HIV-1 in reactive microglia. Acta Neuropathol. 1992;84: 297-306.

39. Deisenhammer F, Miller RF, Brink NS, Harrison MJ, Thompson EJ. Cerebrospinal fluid ferritin in HIV infected patients with acute neurological episodes. Genitourin Med. 1997;73:181-183.

40. Pemberton LA, Brew BJ. Cerebrospinal fluid S-100beta and its relationship with AIDS dementia complex. J Clin Virol. 2001;22:249-253.

41. Hu J, Ferreira A, van Eldik LJ. S100beta induces neuronal cell death through nitric oxide release from astrocytes. J Neurochem. 1997;69:2294-2301.

42. Woods SP, Iudicello JE, Dawson MS, Weber E, Grant I, Letendre SL. $\mathrm{HIV}$-associated deficits in action (verb) generation may reflect astrocytosis. J Clin Exp Neuropsychol. 2009:1-6.

43. Oppenheim JJ, Ruscetti FW. Cytokines. In: Parslow TG, Stites DP, Terr AI, Imboden JB, editors. Medical immunology. New York: Lange Medical Books/McGraw-Hill Medical Publishing; 2001.

44. Gallo P, Frei K, Rordorf C, Lazdins J, Tavolato B, Fontana A. Human immunodeficiency virus type 1 (HIV-1) infection of the central nervous system: an evaluation of cytokines in cerebrospinal fluid. J Neuroimmunol. 1989;23:109-116.

45. Perrella O, Carrieri PB, Guarnaccia D, Soscia M. Cerebrospinal fluid cytokines in AIDS dementia complex. J Neurol. 1992;239:387-388.

46. Gallo P, Laverda AM, de Rossi A, et al. Immunological markers in the cerebrospinal fluid of HIV-1-infected children. Acta Paediatr Scand. 1991;80:659-666.

47. Laverda AM, Gallo P, de Rossi A, et al. Cerebrospinal fluid analysis in HIV-1-infected children: immunological and virological findings before and after AZT therapy. Acta Paediatr. 1994;83:1038-1042.

48. Perrella O, Carreiri PB, Perrella A, et al. Transforming growth factor beta-1 and interferon-alpha in the AIDS dementia complex (ADC): possible relationship with cerebral viral load? Eur Cytokine Netw. 2001;12:51-55.

49. Rieckmann P, Albrecht M, Ehrenreich H, Weber T, Michel U. Semiquantitative analysis of cytokine gene expression in blood and cerebrospinal fluid cells by reverse transcriptase polymerase chain reaction. Res Exp Med (Berl). 1995;195:17-29.

50. Torre D, Zeroli C, Ferraro G, et al. Cerebrospinal fluid levels of IL-6 in patients with acute infections of the central nervous system. Scand J Infect Dis. 1992;24:787-791.

51. Griffin DE, McArthur JC, Cornblath DR. Neopterin and interferongamma in serum and cerebrospinal fluid of patients with HIV-associated neurologic disease. Neurology. 1991;41:69-74.

52. Tyor WR, Glass JD, Griffin JW, et al. Cytokine expression in the brain during the acquired immunodeficiency syndrome. Ann Neurol. 1992;31:349-360.

53. Kolb SA, Sporer B, Lahrtz F, Koedel U, Pfister HW, Fontana A. Identification of a $\mathrm{T}$ cell chemotactic factor in the cerebrospinal fluid of HIV-1-infected individuals as interferon-gamma inducible protein 10 . J Neuroimmunol. 1999;93:172-181.

54. von Giesen HJ, Jander S, Koller H, Arendt G. Serum and cerebrospinal fluid levels of interleukin-18 in human immunodeficiency virus type 1-associated central nervous system disease. J Neurovirol. 2004;10:383-386.

55. Kelder W, McArthur JC, Nance-Sproson T, McClernon D, Griffin DE. Beta-chemokines MCP-1 and RANTES are selectively increased in cerebrospinal fluid of patients with human immunodeficiency virusassociated dementia. Ann Neurol. 1998;44:831-835. 
56. Gallo P, Sivieri S, Rinaldi L, et al. Intrathecal synthesis of interleukin-10 (IL-10) in viral and inflammatory diseases of the central nervous system. J Neurol Sci. 1994;126:49-53.

57. Cosman D. Hematopoietic cell growth factors and their receptors. In: Whetten ADI, DN. Blood Cell Biochemistry. Vol 7. New York: Plenum PRess; 1996.

58. Gruss HJ, Dower SK. Tumor necrosis factor ligand superfamily: involvement in the pathology of malignant lymphomas. Blood. 1995;85:3378-3404.

59. Armitage RJ. Tumor necrosis factor receptor superfamily members and their ligands. Curr Opin Immunol. 1994;6:407-413.

60. Baker SJ, Reddy EP. Transducers of life and death: TNF receptor superfamily and associated proteins. Oncogene. 1996;12:1-9.

61. Lotz M, Terkeltaub R, Villiger PM. Cartilage and joint inflammation. Regulation of IL-8 expression by human articular chondrocytes. J Immunol. 1992;148:466-473.

62. Ware CF, VanArsdale S, VanArsdale TL. Apoptosis mediated by the TNFrelated cytokine and receptor families. J Cell Biochem. 1996;60:47-55.

63. Zoumpourlis V, Eliopoulos AG, Spandidos DA. Transcriptional activation of the human immunodeficiency virus long terminal repeat sequences by tumor necrosis factor. Anticancer Res. 1992;12:2065-2068.

64. Mastroianni CM, Paoletti F, Valenti C, Vullo V, Jirillo E, Delia S. Tumour necrosis factor (TNF-alpha) and neurological disorders in HIV infection. J Neurol Neurosurg Psychiatry. 1992;55:219-221.

65. Achim CL, Heyes MP, Wiley CA. Quantitation of human immunodeficiency virus, immune activation factors, and quinolinic acid in AIDS brains. J Clin Invest. 1993;91:2769-2775.

66. Wesselingh SL, Glass J, McArthur JC, Griffin JW, Griffin DE. Cytokine dysregulation in $\mathrm{HIV}$-associated neurological disease. $A d v$ Neuroimmunol. 1994;4:199-206.

67. Nolting T, Lindecke A, Koutsilieri E, et al. Measurement of soluble inflammatory mediators in cerebrospinal fluid of human immunodeficiency virus-positive patients at distinct stages of infection by solidphase protein array. J Neurovirol. 2009;15:390-400.

68. Mastroianni CM, Paoletti F, Massetti AP, Falciano M, Vullo V. Elevated levels of tumor necrosis factor (TNF) in the cerebrospinal fluid from patients with HIV-associated neurological disorders. Acta Neurol (Napoli). 1990;12:66-67.

69. Sevigny JJ, Albert SM, McDermott MP, et al. Evaluation of HIV RNA and markers of immune activation as predictors of HIV-associated dementia. Neurology. 2004;63:2084-2090.

70. Lafeuillade A, Poggi C, Pellegrino P, Corti K, Profizi N, Sayada C. HIV-1 replication in the plasma and cerebrospinal fluid. Infection. 1996;24:367-371.

71. Franciotta DM, Melzi d'Eril GL, Bono G, Brustia R, Ruberto G, Pagani I. Tumor necrosis factor alpha levels in serum and cerebrospinal fluid of patients with AIDS. Funct Neurol. 1992;7:35-38.

72. Gendelman HE, Zheng J, Coulter CL, et al. Suppression of inflammatory neurotoxins by highly active antiretroviral therapy in human immunodeficiency virus-associated dementia. J Infect Dis. 1998;178:1000-1007.

73. Gisolf EH, van Praag RM, Jurriaans S, et al. Increasing cerebrospinal fluid chemokine concentrations despite undetectable cerebrospinal fluid HIV RNA in HIV-1-infected patients receiving antiretroviral therapy. J Acquir Immune Defic Syndr. 2000;25:426-433.

74. Letendre S, Buzzel M, Marquie-Beck J, Cherner M, Ances B, Ellis RJ, ATH Group: the effects of antiretroviral use on cerebrospinal fluid biomarkers and neuropsychological performance. In 13th Conference on Retroviruses and Opportunistic Infections, Denver, CO; 2006.

75. Campbell IL, Krucker T, Steffensen S, et al. Structural and functional neuropathology in transgenic mice with CNS expression of IFN-alpha. Brain Res. 1999;835:46-61.

76. Sas AR, Bimonte-Nelson H, Smothers CT, Woodward J, Tyor WR. Interferon-alpha causes neuronal dysfunction in encephalitis. J Neurosci. 2009;29:3948-3955.

77. Krivine A, Force G, Servan J, et al. Measuring HIV-1 RNA and interferonalpha in the cerebrospinal fluid of AIDS patients: insights into the pathogenesis of AIDS Dementia Complex. J Neurovirol. 1999;5:500-506.
78. Rho MB, Wesselingh S, Glass JD, et al. A potential role for interferon-alpha in the pathogenesis of HIV-associated dementia. Brain Behav Immun. 1995;9:366-377.

79. Fuchs D, Forsman A, Hagberg L, et al. Immune activation and decreased tryptophan in patients with HIV-1 infection. $J$ Interferon Res. 1990;10:599-603.

80. Shacklett BL, Cox CA, Wilkens DT, et al. Increased adhesion molecule and chemokine receptor expression on $\mathrm{CD}^{+} \mathrm{T}$ cells trafficking to cerebrospinal fluid in HIV-1 infection. J Infect Dis. 2004;189:2202-2212.

81. Probasco JC, Deeks SG, Lee E, et al. Cerebrospinal fluid in HIV-1 systemic viral controllers: absence of HIV-1 RNA and intrathecal inflammation. AIDS. 2010.

82. Cinque P, Bestetti A, Marenzi R, et al. Cerebrospinal fluid interferongamma-inducible protein 10 (IP-10, CXCL10) in HIV-1 infection. J Neuroimmunol. 2005;168:154-163.

83. Weiss JM, Nath A, Major EO, Berman JW. HIV-1 Tat induces monocyte chemoattractant protein-1-mediated monocyte transmigration across a model of the human blood-brain barrier and up-regulates CCR5 expression on human monocytes. J Immunol. 1999;163:2953-2959.

84. Conant K, Garzino-Demo A, Nath A, et al. Induction of monocyte chemoattractant protein-1 in HIV-1 Tat-stimulated astrocytes and elevation in AIDS dementia. Proc Natl Acad Sci US A. 1998;95: 3117-3121.

85. Guillemin GJ, Williams KR, Smith DG, Smythe GA, Croitoru-Lamoury J, Brew BJ. Quinolinic acid in the pathogenesis of Alzheimer's disease. Adv Exp Med Biol. 2003;527:167-176.

86. Sanders VJ, Pittman CA, White MG, Wang G, Wiley CA, Achim CL. Chemokines and receptors in HIV encephalitis. AIDS. 1998;12:1021-1026.

87. Monteiro de Almeida S, Letendre S, Zimmerman J, Lazzaretto D, McCutchan A, Ellis R. Dynamics of monocyte chemoattractant protein type one (MCP-1) and HIV viral load in human cerebrospinal fluid and plasma. J Neuroimmunol. 2005;169:144-152.

88. Avison MJ, Nath A, Greene-Avison R, et al. Inflammatory changes and breakdown of microvascular integrity in early human immunodeficiency virus dementia. J Neurovirol. 2004;10:223-232.

89. Bernasconi S, Cinque P, Peri G, et al. Selective elevation of monocyte chemotactic protein-1 in the cerebrospinal fluid of AIDS patients with cytomegalovirus encephalitis. J Infect Dis. 1996;174:1098-1101.

90. Cinque P, Vago L, Mengozzi M, et al. Elevated cerebrospinal fluid levels of monocyte chemotactic protein-1 correlate with HIV-1 encephalitis and local viral replication. AIDS. 1998;12:1327-1332.

91. Sozzani S, Introna M, Bernasconi S, et al. MCP-1 and CCR2 in HIV infection: regulation of agonist and receptor expression. J Leukoc Biol. 1997;62:30-33.

92. He J, Chen Y, Farzan M, et al. CCR3 and CCR5 are co-receptors for HIV-1 infection of microglia. Nature. 1997;385:645-649.

93. Sasseville VG, Smith MM, Mackay CR, et al. Chemokine expression in simian immunodeficiency virus-induced AIDS encephalitis. Am J Pathol. 1996;149:1459-1467.

94. Westmoreland SV, Rottman JB, Williams KC, Lackner AA, Sasseville VG. Chemokine receptor expression on resident and inflammatory cells in the brain of macaques with simian immunodeficiency virus encephalitis. Am J Pathol. 1998;152:659-665.

95. Hesselgesser J, Horuk R. Chemokine and chemokine receptor expression in the central nervous system. J Neurovirol. 1999;5:13-26.

96. Schmidtmayerova H, Nottet HS, Nuovo G, et al. Human immunodeficiency virus type 1 infection alters chemokine beta peptide expression in human monocytes: implications for recruitment of leukocytes into brain and lymph nodes. Proc Natl Acad Sci U S A. 1996;93: $700-704$.

97. Letendre SL, Lanier ER, McCutchan JA. Cerebrospinal fluid beta chemokine concentrations in neurocognitively impaired individuals infected with human immunodeficiency virus type 1. J Infect Dis. 1999;180:310-319.

98. Re DB, Przedborski S. Fractalkine: moving from chemotaxis to neuroprotection. Nat Neurosci. 2006;9:859-861. 
99. Erichsen D, Lopez AL, Peng H, et al. Neuronal injury regulates fractalkine: relevance for HIV-1 associated dementia. JNeuroimmunol. 2003;138:144-155.

100. Sporer B, Kastenbauer S, Koedel U, Arendt G, Pfister HW. Increased intrathecal release of soluble fractalkine in HIV-infected patients. AIDS Res Hum Retroviruses. 2003;19:111-116.

101. Letendre S, Zheng J, Yiannoutsos C, et al. Chemokines correlate with cerebral metabolites on magnetic resonance spectroscopy: a sub study of ACTG 301 and 700. 11th COnference on Retroviruses and Opportunistic Infections. San Francisco, CA; 2004.

102. Scorziello A, Florio T, Bajetto A, Thellung S, Schettini G. TGFbeta1 prevents gp120-induced impairment of $\mathrm{Ca} 2^{+}$homeostasis and rescues cortical neurons from apoptotic death. $J$ Neurosci Res. 1997;49:600-607.

103. Johnson MD, Kim P, Tourtellotte W, Federspiel CF. Transforming growth factor beta and monocyte chemotactic protein-1 are elevated in cerebrospinal fluid of immunocompromised patients with HIV-1 infection. J Neuro AIDS. 2004;2:33-43.

104. Nebuloni M, Cinque P, Sidenius N, et al. Expression of the urokinase plasminogen activator receptor (UPAR) and its ligand (uPA) in brain tissues of human immunodeficiency virus patients with opportunistic cerebral diseases. J Neurovirol. 2009;15:99-107.

105. Cinque P, Nebuloni M, Santovito ML, et al. The urokinase receptor is overexpressed in the AIDS dementia complex and other neurological manifestations. Ann Neurol. 2004;55:687-694.

106. Brew BJ, Pemberton L, Cunningham P, Law MG. Levels of human immunodeficiency virus type 1 RNA in cerebrospinal fluid correlate with AIDS dementia stage. J Infect Dis. 1997;175:963-966.

107. Ellis RJ, Hsia K, Spector SA, et al. Cerebrospinal fluid human immunodeficiency virus type 1 RNA levels are elevated in neurocognitively impaired individuals with acquired immunodeficiency syndrome. HIV Neurobehavioral Research Center Group. Ann Neurol. 1997;42:679-688.

108. Karlsson U, Antonsson L, Repits J, et al. Mode of coreceptor use by R5 HIV type 1 correlates with disease stage: a study of paired plasma and cerebrospinal fluid isolates. AIDS Res Hum Retroviruses. 2009;25: 1297-1305.

109. McArthur JC, McClernon DR, Cronin MF, et al. Relationship between human immunodeficiency virus-associated dementia and viral load in cerebrospinal fluid and brain. Ann Neurol. 1997;42:689-698.

110. Ellis RJ, Gamst AC, Capparelli E, et al. Cerebrospinal fluid HIV RNA originates from both local CNS and systemic sources. Neurology. 2000;54:927-936.

111. Ellis RJ, Moore DJ, Childers ME, et al. Progression to neuropsychological impairment in human immunodeficiency virus infection predicted by elevated cerebrospinal fluid levels of human immunodeficiency virus RNA. Arch Neurol. 2002;59:923-928.

112. Cysique LA, Maruff P, Brew BJ. Variable benefit in neuropsychological function in HIV-infected HAART-treated patients. Neurology. 2006;66:1447-1450.

113. Shiramizu B, Lau E, Tamamoto A, Uniatowski J, Troelstrup D. Feasibility assessment of cerebrospinal fluid from HIV-1-infected children for HIV proviral DNA and monocyte chemoattractant protein 1 alleles. J Investig Med. 2006;54:468-472.

114. Cherner M, Letendre S, Heaton RK, et al. Hepatitis C augments cognitive deficits associated with HIV infection and methamphetamine. Neurology. 2005;64:1343-1347.

115. Letendre SL, Cherner M, Ellis RJ, et al. The effects of hepatitis C, HIV, and methamphetamine dependence on neuropsychological performance: biological correlates of disease. AIDS. 2005;19(Suppl 3):S72-S78.

116. Riedel DJ, Pardo CA, McArthur J, Nath A. Therapy Insight: CNS manifestations of HIV-associated immune reconstitution inflammatory syndrome. Nat Clin Pract Neurol. 2006;2:557-565.

117. Shiramizu B, Gartner S, Williams A, et al. Circulating proviral HIV DNA and HIV-associated dementia. AIDS. 2005;19:45-52.

118. Shiramizu B, Ratto-Kim S, Sithinamsuwan P, et al. HIV DNA and dementia in treatment-naive HIV-1-infected individuals in Bangkok, Thailand. Int J Med Sci. 2007;4:13-18.
119. Crews L, Patrick C, Achim CL, Everall IP, Masliah E. Molecular pathology of neuro-AIDS (CNS-HIV). Int J Mol Sci. 2009;10:1045-1063.

120. Griffin DE, Wesselingh SL, McArthur JC. Elevated central nervous system prostaglandins in human immunodeficiency virus-associated dementia. Ann Neurol. 1994;35:592-597.

121. Giovannoni G, Miller RF, Heales SJ, Land JM, Harrison MJ, Thompson EJ. Elevated cerebrospinal fluid and serum nitrate and nitrite levels in patients with central nervous system complications of HIV-1 infection: a correlation with blood-brain-barrier dysfunction. J Neurol Sci. 1998;156:53-58.

122. Giovannoni G, Heales SJ, Silver NC, et al. Raised serum nitrate and nitrite levels in patients with multiple sclerosis. J Neurol Sci. 1997;145:77-81.

123. Milstien S, Sakai N, Brew BJ, et al. Cerebrospinal fluid nitrite/nitrate levels in neurologic diseases. J Neurochem. 1994;63:1178-1180.

124. Li W, Malpica-Llanos TM, Gundry R, et al. Nitrosative stress with HIV dementia causes decreased L-prostaglandin D synthase activity. Neurology. 2008;70:1753-1762.

125. Epstein LG, Gelbard HA. HIV-1-induced neuronal injury in the developing brain. J Leukoc Biol. 1999;65:453-457.

126. Bazan NG, Packard MG, Teather L, Allan G. Bioactive lipids in excitatory neurotransmission and neuronal plasticity. Neurochem Int. 1997;30:225-231.

127. Bito H, Nakamura M, Honda Z, et al. Platelet-activating factor (PAF) receptor in rat brain: PAF mobilizes intracellular $\mathrm{Ca}_{2}{ }^{+}$in hippocampal neurons. Neuron. 1992;9:285-294.

128. Franconi F, Miceli M, de Montis MG, Crisafi EL, Bennardini F, Tagliamonte A. NMDA receptors play an anti-aggregating role in human platelets. Thromb Haemost. 1996;76:84-87.

129. Tsoupras AB, Chini M, Tsogas N, et al. Anti-platelet-activating factor effects of highly active antiretroviral therapy (HAART): a new insight in the drug therapy of HIV infection? AIDS Res Hum Retroviruses. 2008;24:1079-1086.

130. Eggert D, Dash PK, Serradji N, et al. Development of a plateletactivating factor antagonist for HIV-1 associated neurocognitive disorders. J Neuroimmunol. 2009;213:47-59.

131. Marshall DW, Brey RL, Butzin CA, Lucey DR, Abbadessa SM, Boswell RN. CSF changes in a longitudinal study of 124 neurologically normal HIV-1-infected US. Air Force personnel. J Acquir Immune Defic Syndr. 1991;4:777-781

132. Norgren N, Rosengren L, Stigbrand T. Elevated neurofilament levels in neurological diseases. Brain Res. 2003;987:25-31.

133. Abdulle S, Mellgren A, Brew BJ, et al. CSF neurofilament protein (NFL) - a marker of active HIV-related neurodegeneration. J Neurol. 2007;254:1026-1032.

134. Gisslen M, Rosengren L, Hagberg L, Deeks SG, Price RW. Cerebrospinal fluid signs of neuronal damage after antiretroviral treatment interruption in HIV-1 infection. AIDS Res Ther. 2005;2:6.

135. Gisslen M, Hagberg L, Brew BJ, Cinque P, Price RW, Rosengren L. Elevated cerebrospinal fluid neurofilament light protein concentrations predict the development of AIDS dementia complex. J Infect Dis. 2007;195:1774-1778.

136. Mellgren A, Price RW, Hagberg L, Rosengren L, Brew BJ, Gisslen M. Antiretroviral treatment reduces increased CSF neurofilament protein (NFL) in HIV-1 infection. Neurology. 2007;69:1536-1541.

137. Brettschneider J, Petzold A, Schottle D, Claus A, Riepe M, Tumani H The neurofilament heavy chain $(\mathrm{NfH})$ in the cerebrospinal fluid diagnosis of Alzheimer's disease. Dement Geriatr Cogn Disord. 2006;21:291-295.

138. Petzold A, Eikelenboom MJ, Gveric D, et al. Markers for different glial cell responses in multiple sclerosis: clinical and pathological correlations. Brain. 2002;125:1462-1473.

139. Petzold A, Hinds N, Murray NM, et al. CSF neurofilament levels: a potential prognostic marker in Guillain-Barre syndrome. Neurology. 2006;67:1071-1073.

140. Gisslen M, Krut J, Andreasson U, et al. Amyloid and tau cerebrospinal fluid biomarkers in HIV infection. BMC Neurol. 2009;9:63. 
141. Andreasen N, Sjogren M, Blennow K. CSF markers for Alzheimer's disease: total tau, phospho-tau and Abeta42. World J Biol Psychiatry. 2003;4:147-155.

142. Brew BJ, Pemberton L, Blennow K, Wallin A, Hagberg L. CSF amyloid beta42 and tau levels correlate with AIDS dementia complex. Neurology. 2005;65:1490-1492.

143. Clifford DB, Fagan AM, Holtzman DM, et al. CSF biomarkers of Alzheimer disease in HIV-associated neurologic disease. Neurology. 2009; 73:1982-1987.

144. Bandaru VV, McArthur JC, Sacktor N, et al. Associative and predictive biomarkers of dementia in HIV-1-infected patients. Neurology. 2007;68:1481-1487.

145. Abdulle S, Hagberg L, Gisslen M. Effects of antiretroviral treatment on blood-brain barrier integrity and intrathecal immunoglobulin production in neuroasymptomatic HIV-1-infected patients. HIV Med. 2005;6:164-169.

146. Hall CD, Snyder CR, Robertson KR, et al. Cerebrospinal fluid analysis in human immunodeficiency virus infection. Ann Clin Lab Sci. 1992;22:139-143.

147. Singer EJ, Syndulko K, Fahy-Chandon B, Schmid P, Conrad A, Tourtellotte WW. Intrathecal IgG synthesis and albumin leakage are increased in subjects with HIV-1 neurologic disease. JAcquir Immune Defic Syndr. 1994;7:265-271.

148. Andersson LM, Hagberg L, Fuchs D, Svennerholm B, Gisslen M. Increased blood-brain barrier permeability in neuro-asymptomatic HIV-1-infected individuals - correlation with cerebrospinal fluid HIV-1 RNA and neopterin levels. J Neurovirol. 2001;7:542-547.

149. Sporer B, Koedel U, Paul R, Eberle J, Arendt G, Pfister HW. Vascular endothelial growth factor (VEGF) is increased in serum, but not in cerebrospinal fluid in HIV associated CNS diseases. $J$ Neurol Neurosurg Psychiatry. 2004;75:298-300.
150. Huang SH, Jong AY. Cellular mechanisms of microbial proteins contributing to invasion of the blood-brain barrier. Cell Microbiol. 2001;3:277-287.

151. Heidenreich F, Arendt G, Jander S, Jablonowski H, Stoll G. Serum and cerebrospinal fluid levels of soluble intercellular adhesion molecule 1 (sICAM-1) in patients with HIV-1 associated neurological diseases. J Neuroimmunol. 1994;52:117-126.

152. Rieckmann P, Nunke K, Burchhardt M, et al. Soluble intercellular adhesion molecule-1 in cerebrospinal fluid: an indicator for the inflammatory impairment of the blood-cerebrospinal fluid barrier. J Neuroimmunol. 1993;47:133-140.

153. Rosenberg GA. Matrix metalloproteinases in neuroinflammation. Glia. 2002;39:279-291.

154. Sporer B, Paul R, Koedel U, et al. Presence of matrix metalloproteinase-9 activity in the cerebrospinal fluid of human immunodeficiency virusinfected patients. J Infect Dis. 1998;178:854-857.

155. Conant K, McArthur JC, Griffin DE, Sjulson L, Wahl LM, Irani DN. Cerebrospinal fluid levels of MMP-2, 7, and 9 are elevated in association with human immunodeficiency virus dementia. Ann Neurol. 1999;46:391-398.

156. Liuzzi GM, Mastroianni CM, Santacroce MP, et al. Increased activity of matrix metalloproteinases in the cerebrospinal fluid of patients with HIV-associated neurological diseases. J Neurovirol. 2000; 6:156-163.

157. Rozek W, Ricardo-Dukelow M, Holloway S, et al. Cerebrospinal fluid proteomic profiling of HIV-1-infected patients with cognitive impairment. J Proteome Res. 2007;6:4189-4199.

158. Laspiur JP, Anderson ER, Ciborowski P, et al. CSF proteomic fingerprints for HIV-associated cognitive impairment. J Neuroimmunol. 2007;192:157-170.
Neurobehavioral HIV Medicine

\section{Publish your work in this journal}

Neurobehavioral HIV Medicine is an international, peer-reviewed, open access journal focusing on advances in research in HIV/ AIDS, with specific reference to the neurological, psychiatric and behavioral consequences of the disease, concomitant infections and specific antiretroviral therapy. The manuscript

\section{Dovepress}

management system is completely online and includes a very quick and fair peer-review system, which is all easy to use. Visit http://www.dovepress.com/testimonials.php to read real quotes from published authors. 